\title{
MATERIALS PROCESSING WITH A HIGH POWER DIODE LASER
}

\author{
L. Li*, J.Lawrence* and J.T.Spencer** \\ * Manufacturing Division, Department of Mechanical Engineering, UMIST, Sackville Street, Manchester M60 \\ 1QD, UK
}

** Company Research Laboratory, British Nuclear Fuels Plc. Springfield Works, Preston

Lancashire PR4 OXJ, UK

\begin{abstract}
Laser materials processing is currently dominated by $\mathrm{CO}_{2}, \mathrm{Nd}-\mathrm{YAG}$ and Excimer lasers. Continuous advances in semiconductor laser technology over the last decade have increased the average power output of the devices annualy by two fold, resulting in the commercial availability of the diode lasers today with delivery output powers in excess of $60 \mathrm{~W}$ in $\mathrm{CW}$ mode and $5 \mathrm{~kW}$ in qasi-CW mode. The advantages of compactness, high reliability, high efficiency and potential low cost, due to the mass production capability of the diode laser, will inextricably shape its future in the field of materials processing. This papers reports on work exploring the feasibility of a range of materials processing applications using a Diomed $60 \mathrm{~W}$ diode laser, transmitted through a $600 \mu \mathrm{m}$ diameter optical fibre and coupled to a 3 axis CNC workstation. The applications studied include; marking and engraving natural stones (marble and granite), marking ceramic tiles, glazing and sealing tile grouts, marking and cutting glass, marking wood, welding metal wire and transformation hardening of tool steels. The study shows that even at the present limited power level of diode laser, many materials processing applications can be accomplished with satisfactory results. Through the study an initial understanding of interaction of diode laser beam with various materials has been gained. Also, within the paper basic beam characteristics, the state of the art of high power diode laser technology and current materials processing applications are also reviewed.
\end{abstract}

\section{INTRODUCTION}

Laser materials processing is currently primarily based on $\mathrm{CO}_{2}$, Nd-YAG and Excimer lasers. These lasers coexist within the materials processing market because each of them posesses unique and complementary features. For example, $\mathrm{CO}_{2}$ lasers have the advantages of high quantum efficiency (up to $15 \%$ ), high average power (up to $25 \mathrm{~kW}$ ) with good mode structure normally (for lasers less than $5 \mathrm{~kW}$ ) and good beam absorption for non-metallic materials. $\mathrm{CO}_{2}$ lasers are thus often used for sheet metal cutting and the processing of non-metallic materials. Nd-YAG lasers have the advantages of being able to transmit through optical fibres and can usually provide high peak powers (up to $100 \mathrm{~kW}$ ) pulsed beam with average powers up to $3 \mathrm{~kW}$. Thus they are suitable for the marking and drilling of metallic components and multi-axis robotic welding. Excimer lasers produces UV beams of ns pulse and over $10 \mathrm{MWs}$ of peak power with reasonably good average power (up to $1 \mathrm{~kW}$ ) which is well suitable for micro-machining and surface ablation with little heat effect on the underlying materials. Other lasers used for materials processing include CO laser, copper vapour laser and COIL laser. A common problem with these lasers is that they are all bulky and require high maintenance cost and high running cost.

The High Power Laser Diode (HPLD) however, is based on semiconductor technology. It provides the highest quantum efficiency (up to $40 \%$ ), is compact (few $\mathrm{cm}^{2}$ for $500 \mathrm{~W} \mathrm{CW}$ power), very reliable (almost maintenance free) with optical fibre delivery, has extremely low running costs, has a very long life (over 50,000 hours) and is a low voltage device $(5-12 \mathrm{~V})$ and could therefore be run on bateries. A comparison of the HPLD with $\mathrm{CO}_{2}$, $\mathrm{Nd}$ :YAG and Excimer lasers is given in Table 1. Considering the unique features of the HPLD it is believed by the authors that the HPLD will establish a significant share of the materials processing market in the near future. 
Table 1. A comparison of the principal features of HPLD with other lasers for materials processing.

\begin{tabular}{|c|c|c|c|}
\hline $\begin{array}{c}\text { Type of } \\
\text { lasers }\end{array}$ & Unique features & Principal weakness & Typical applications \\
\hline $\mathrm{CO}_{2}$ laser & $\begin{array}{ll}\text { - } & \text { highest average power } \\
& \text { (up to } 25 \mathrm{~kW}) \\
\text { - } & \text { high efficiency }(15 \%) \\
\text { - } & \text { good beam mode }\end{array}$ & $\begin{array}{l}\text { beam can not be } \\
\text { delivered using optical } \\
\text { fibres }\end{array}$ & $\begin{array}{l}\text { Sheet metal cutting, non- } \\
\text { metallic materials marking, } \\
\text { welding, surface treatments }\end{array}$ \\
\hline $\begin{array}{l}\text { Nd-YAG } \\
\text { laser }\end{array}$ & $\begin{array}{l}\text { - } \text { high peak power of } \\
\text { pulsed beam } \\
\text { - } \quad \text { beam transmittable } \\
\text { through optical fibres }\end{array}$ & $\begin{array}{ll}\text { - } & \text { poor beam mode (for } \\
\text { arc lamp exctied } \\
\text { system) } \\
\text { - } \quad \text { surface colour sensitive } \\
\text { - } \quad \text { high safety requirement }\end{array}$ & $\begin{array}{l}\text { Metal marking, drilling, multi- } \\
\text { axis robotic welding, machining } \\
\text { and paint stripping etc. }\end{array}$ \\
\hline $\begin{array}{l}\text { Excimer } \\
\text { laser }\end{array}$ & $\begin{array}{l}\text { - } \text { highest peak power } \\
\text { - } \text { very short pulse (ns) } \\
\text { - } \text { UV wavelength }\end{array}$ & $\begin{array}{l}\text { - very high cost to install } \\
\text { and to run } \\
\text { - very high safety } \\
\text { requirement }\end{array}$ & $\begin{array}{l}\text { Micro-machining, surface } \\
\text { cleaning, ablation, PVD, CVD } \\
\text { etc. }\end{array}$ \\
\hline HPLD & $\begin{array}{ll}\text { - } & \text { very compact/portable } \\
\text { - } & \text { highest quantum } \\
\text { efficiency (up to } 50 \% \text { ) } \\
\text { - } & \text { very long life (up to } \\
& 100000 \text { hrs) } \\
\text { - } & \text { lowest running cost } \\
\text { - } & \text { almost maintenance free } \\
\text { - } & \text { wavelength tuneable } \\
\text { - } & \text { low voltage device }\end{array}$ & $\begin{array}{ll}\text { - } & \text { poor beam mode } \\
\text { - } & \text { surface colour sensitive } \\
\text { - } & \text { high safety requirement } \\
\text { - } & \text { wide spectrum line } \\
\text { - } & \text { width } \\
\text { - } & \text { currently high cost } \\
\text { currently limited power }\end{array}$ & $\begin{array}{l}\text { Soldering, glazing, marking, } \\
\text { engraving, micro-welding }\end{array}$ \\
\hline
\end{tabular}

Since its advent in 1962, despite is inherent advantages, the diode laser is only now increasing its number of applications. Such applications are dominated by the shorter wavelength, low power devices (630-850nm), and include CD audio system, CD-ROM, telecommunication, bar-code scanners, metrology and laser printers. Rapid and continuous enhancement of diode laser materials and fabrication technology over the last decade has increased the average power output of the devices by two fold each year, giving rise today to the commercial availability of diode lasers with output powers in excess of $200 \mathrm{~mW}$ - high power laser diodes (HPLD), up to $100 \mathrm{~W}$ CW power for optical fibre delivery systems and $5 \mathrm{~kW}$ quasi-CW diode laser stacks [1]. Currently the predominant function of the HPLD is the pumping of solid-state lasers, usually Nd-YAG, because of its higher efficiency (increasing the overall conversion efficiency from $2 \%$ to $10 \%$ ), increased reliability ( $>3000 \%$ increase in life) and improved beam quality [2]. Also, HPLD are found extensively within medicine, where they are used in the treatment of many ailments, from simple ear, nose and throat operations to cancer ablation [3].

Notwithstanding such advances, the proliferation of HPLD into more application areas, especially in materials processing, has been held in check by its prohibitively high price; currently $£ 500$ per CW watt for optical fibre beam delivery laser diode systems and $£ 200$ per CW watt for OEM diode stacks, compared to $£ 35, £ 150$ and $£ 900$ per $\mathrm{cw}$ watt for $\mathrm{CO}_{2}$, YAG and excimer lasers respectively. At present the direct application of HPLD for materials processing is limited to soldering [4-6], hardening [7] and ceramic metal powder sintering [7]. However, HPLD materials processing is an active field of research that may expand rapidly over the next decade as the $30 \%-50 \%$ p.a. price reduction continuous. Because semi-conductors, and hence laser diodes, can be mass produced, large economies of scale fuelled by demand can be realised by manufacturers. As a result laser diodes have the potential to become extremely inexpensive. As such, the emergence of the HPLD as one of the principal laser materials processing tool is a distinct future possibility.

\section{LASER BEAM PROPERTIES AND RECENT DEVELOPMENTS IN HPLD TECHNOLOGY}

\subsection{Basic laser configrations and commercial HPLD systems}

High power diode lasers are based on semiconductors of Group III-V compounds (such as gallium arsenide and indium phosphide). At the P-N junction of two semiconductors that have been doped with either a pentevalent or 
a trivalent element, there exists a charge barrier of height $\mathrm{eV}_{0}$ due to the natural occurrence of a charge separation. The application of an external potential, $\mathrm{V}$, in the direction of electron flow causes the height of the charge barrier to reduce to e $\left(\mathrm{V}_{0}-\mathrm{V}\right)$, and causes the electrons to flow across the junction. Once across they are in excess and recombine with carriers of the opposite type by simply falling back into the valence band. As an electron recombines it will spontaneously emit a photon as in LED. If doping at the p-n junction is sufficient, and a high enough current is applied, it is possible to achieve a population inversion. By enclosing this junction in an optical cavity laser radiation can be sustained. The refractive index of semiconductors is quite high at their emission wavelength, so there is sufficient reflection at seomiconductor/air interface to form an active cavity. The confinement of the laser beam in the lateral directions is realised by either gain guiding or index guiding. In the gain guided diode laser lasing is confined by the flux of the charge carriers at the junction, which is defined by the strip shape of electrodes. This type of laser is easier to manufacture. In the index guided laser, radiation is confined to a waveguided groove formed close to the active junction. This type of laser has superior optical properties. The majority of current HPLD are index guided.

A single diode has very limited power $(<60 \mathrm{~mW})$. Thus commercial high power diode lasers are either based on one dimesional linear array (a bar of around $1 \mathrm{~cm}$ long stacked with 15-150 diodes on a single sub-assembly) or two dimensional multi-laser arrays (several 1-D bars in a stack). Therefore, there is no limit on the maximum power diode laser stacks can deliver. Currently a few $\mathrm{cm}^{2}$ diode stack can deliver up to 500W $\mathrm{CW}$ optical power and 5kW Q-CW optical power [1].

HPLD are usually driven with a current source (currently up to $130 \mathrm{~A})$ with low voltage $(<20 \mathrm{~V}$ for CW diodes and $<100 \mathrm{~V}$ for Qausi-CW laser diodes ). Thus diode lasers have less electrical risks associated with them than other high power lasers, and can sometimes be run on batteries. The typical size of the HPLD driver is comparable to a PC computer deck. The life of the diode laser is over 50,000 hours, many times longer than other high power lasers.

Commercial HPLD systems are either in a stack form for OEM applications or fibre optical delivered systems for non-OEM users. Companies that manufacture or supply high power diode laser stacks (up to $5 \mathrm{~kW}$ Q-CW, duty factor of $1-20 \%$, beam divergence of 10 to 40 degrees FWHM) or optical fibre delivered systems (up to $100 \mathrm{~W}$ CW, 0.2 to 0.4 NA, 200 to $2000 \mu \mathrm{m}$ core fibre) include SDL, Opto Power Corp., AT\&T Bell in USA, Sony Corp. in Japan, GEC, Diomed Ltd., Spectra Physics, Laser Lines (supplier), AMS Electronics (suplier), and Pacer Components Ltd. (supplier) in UK. CeramOptec GmbH and Jenoptik Laser Diode GmbH in Germany and Tutcore in Finland.

\subsection{Optical charateristics of HPLD relavent to materials processing}

HPLD have many special optical properties that are different from other types of high power lasers. These properties include wide spectrum band, high beam divergence, non-symmectric beam distribution and astigmatism.

Wavelength: It is know that optical energy absorption by materials and beam focuaability are dependent on the laser beam wavelength. The wavelength at which diode lases emit at is dependent upon the bandgap energy, cavity length and index of refraction of the semiconductor, thus is material dependent. The most common compounds and their emitting wavelengths are given in table 2:

Table 2. Diode laser wavelength for different materials.

\begin{tabular}{|c|c|}
\hline Semiconductor Compound & Wavelength $(\mathrm{nm})$ \\
\hline GaAlAs & $720-880$ \\
\hline InGaAs & $940-990$ \\
\hline AlGaInP & $630-690$ \\
\hline
\end{tabular}

Diode laser wavelength is also strongly influenced by temperature, up to $0.4 \mathrm{~nm} /{ }^{\circ} \mathrm{C}$ [8] which affects all of the three factors mentioned above. Therefore commercial diode lasers have very precise temperature control. This feature can also be used for the wavelength tuning of the diode laser. The diode laser wavelength is further affected by the driving current, typically $0.025 \mathrm{~nm} / \mathrm{mA}$ [8]. Therefore varying the power of the diode laser may well cause the variation of laser wavelength. When individual laser diodes are stacked to form a high power stack further increase spectrum bandwidth of the combined beam is expected. Typical sprectum bandwidth of a high power diode laser stack is $2-20 \mathrm{~nm}$. 
Beam divergence and assymetry: Most currently avialble diode lasers are edge emitting devices, with a FabryPerot lasing cavity, with its length determined by the length of the ship and transverse dimensions defined by an index guided process or a gain guided process. These very small and asymmetric dimesions result in 20 to $40^{\circ}$ half angle divergence in the direction perpendicular to the facet of the laser and 2.5 to 6 times smaller divergence in the parallel axis [8]. Thus the beam is aymmetric and diverges into an elliptical cone. Therefore the laser beams from a signle diode chip or diode array are not directly usable for materials processing. Usally a specially desinged collimating lens system (e.g. a high numerical aperture spherical lens group) and a cylindrical lens telescope or an anamorphic prism pair have to be used for the beam shaping in order to achieve a low divergence $\left(1-2^{\circ}\right.$ half angle $)$ symmetric beam. Since beam digergence parameters vary significantly from laser to laser, the collimating and beam shaping opics have to be designed specifically for each case. When an optical fibre is used to collect the laser beam, assymetry will not affect the beam output since the beam is homogenised through the fibre.

Astigmatism : Unlike most of the other materials processing lasers, the diode laser beam is astigmatic. This is caused by the longitudinal separation (around $5 \mu \mathrm{m}$ for index guided diode lasers) between the the diode laser's emission points parallel and perpendicular to the junction. This is due to the directional dependence of the refractive index of the lasing cavity. Astigmatism will affect the beam divergence and beam focus for materials processing. Usually a weak cylindrical lens is inserted in the beam parth at an anagle to correct this. The use of optical fibre beam delivery may reduce this effect by homogenisation.

Polarizartion: Diode lasers are lineraly polarized with an electrical vecrtor parallel to the diode laser juntion. It is known that polarisation will affect laser cutting in different directions. Therefore direct use of diode laser beam for omni-materials processing (without using optical fibre beam delivery) would requre a depolariser (phase retarder) to change it to a circular polarised beam.

From the above analysis, it can be seen that there is a great advantage in using an optical fibre delivered diode laser beam for materials processing. However, since the output laser beam is the combination of those coming from a number of laser diode emitters, a highly incoherent multimode output beam will result. The minimum beam spot size that can be focused after the optical fibre delivery is usually limited to the core size of the optical fibre, which is usually greater than $0.5 \mathrm{~mm}$ for lasers of over $50 \mathrm{~W}$ power.

\subsection{Recent HPLD developments}

It is impossible to include all the literature on the subject in this paper. Some main areas of development are given below.

Beam shaping techniques: Clarkson et al [9] at the University of Southampton, UK have developed a multiple relfection beam shaping technqiue that will focus laser diode bar output to a low divergence, circular spot of $200 \mathrm{~mm}$ in diameter. Liau et al [10], at the Massachusetts Institute of Technology are developing accurate anamorphic microlenses that will efficiently collimate the inherehnt astigmatic output of tappered unstable resonator diode lasers, thus allowing the beam to focus down to a circular spot closed to that of the fudemental mode. Bayer et al [11] at Franhofer Institute fur Laser Technik, Germany studied the possibility of producing the laser beam profile delivered from a bundle of optical fibres by controlling the power input to each optical fibre.

Vertical-Cavity Surface Emitting Laser Diode (VCSELD) arrays and phase locking: VCSELD arrays emit a circular symmetric output beam of around from a facet perpendicular to the active jucnction. As such the emitting aera is larger and thus higher brightness is obtained. VCSELD arrays can be mass produced at low cost as monolithic 2-D wafers. Phase locking of 2-D VCSELD arrays has been achieved by employing grid contacts [12], patterned mirrors [13] phase shifter array [7] and in external Talbot cavity structures [14].

\section{PREVIOUS WORK ON USING HPLD FOR MATERIALS PROCESSING}

There have been a very limited R\&D activities on using HPLD for materials processing with the first reported work in 1991. The cited materials are briefly described in the following.

Soldering: Initial studies by Polijanczuk et al [4] at Hull University, UK, and later work by Krause et al [15] at the Franhoffer-Institue fur Lasertechnik, Germany, and by a team at McDonnell Douglas Aerospace, USA [16] into soldering using fibre and optically coupled HPDL has established the feasibility of the process. This has been further developed into a commercial system for surface mount soldering by Sony in Japan, Hull University 
and Diomed Ltd, UK and McDonnell Douglas Aerospace, USA, delivering 10-50W output power through 1mm fibre bundles $[3,5,16,17]$. Research by Tonshoff et al [6] at the Laser Zentrum Hannover eV., Germany has investigated the use of HPLD for soft soldering of copper foils and the contacts of electronic components on PCB's. Soldering is up to now the only successful commercial material processing application using HPLD.

Sintering metal-ceramic powders: The sintering of metal or ceramic powders to manufacture precision machine parts using lasers is expected to be an extremely important segment of desktop manufacturing and rapid prototyping. Such an application would be highly suitable for a low cost HPLD system. Preliminary work by Chen et al [7] at the University of Connecticut, with a fibre coupled HPLD system emitting a maximum output power of $25 \mathrm{~W}$ with a beam spot diameter of 0.5 to $1 \mathrm{~mm}$, showed that with an accurately controlled dwell time even alumna powders could be successfully sintered. As yet no actual results of the these experiments have been published.

Hardening stainless steel: Work by Chen et al [7] showed that 400 series stainless steel tape with a thickness of $0.1 \mathrm{~mm}$ and width of $6 \mathrm{~mm}$ could be hardened by using a $15 \mathrm{~W}$ diode laser with $1 \mathrm{~mm}$ spot diameter and exposure time of 3 seconds, followed by auxiliary cooling. An increase of hardness in the high temperature region of the sample was achieved.

Cutting and drilling: The cutting and drilling of various materials has been investigated by Toshoff et al [6] at Laser Zentrum Hannover e.V. Germany, and by McDonnell Douglas Aerospace, USA [16]. The materials studied included stainless steel ( $1 \mathrm{~mm}$ thickness), steel ( $0.5 \mathrm{~mm}$ thickness), aluminium $(0.25 \mathrm{~mm}$ thickness), copper $(0.25 \mathrm{~mm}$ thickness), plastics, epoxy, paper and wood with maximum laser power of $45 \mathrm{~W}$ and spot size of $0.5 \mathrm{~mm}$ and typical cutting speed of $4 \mathrm{~mm} / \mathrm{s}$. A detailed report on the effect of cut (such as HAZ, dross, kerf width etc.) were not given. It has been recognised that due to the large focused beam size of the HPLD the efficiency of laser cutting is not particularly good compared to other types of lasers.

Welding stainless steel and carbon steel sheets: McDonnell Douglas Aerospace has demonstrated the welding of stainless steel and carbon steel sheets using a 50W HPLD at $2 \mathrm{~mm} / \mathrm{min}$ welding speed [16]. The efficiency of welding is shown to be very low and the heat affected zone is very high compared to other lasers.

Marking on metals: McDonnell Douglas Aerospace has investigated the feasibility of marking on stainless steel, anodised aluminium and aluminium using a 50W HPLD [16]. The effect of marking was not reported.

\section{NEW DEVELOPMENTS AT UMIST FOR HPLD MATERIALS PROCESSING}

\subsection{Equipment description}

Research work at UMIST on materials processing using high power diode lasers started in April 1995 with both industrial and government funding. A Diodmed $60 \mathrm{~W} \mathrm{CW}$ diode laser system was installed at UMIST with supporting beam focusing optics (1:1 and 1:2), processing nozzle and an Unimatic Engineering 3-axis CNC workstation coupled to a $\mathrm{CAD} / \mathrm{CAM}$ (Virtual Gibbs) system. The laser beam was delivered to the processing head (lens and nozzle assembly) through an armoured optical fibre with $1000 \mu \mathrm{m}$ core diameter. The laser is based on GaAlAs semiconductor laser arrays radiating $810 \mathrm{~nm} \pm 20 \mathrm{~nm}$ infrared beams. A visible diode laser of $650 \mathrm{~nm}$ was used coaxal to the main diode laser beam as an aiming beam. The power supply to the diode laser system is directly from a $240 \mathrm{~V}$ AC mains. No water cooling of the laser system is required for the system. Research was carried out to study areas of materials processing that have not been reported in the public literature and those suitable to the present power levels of the diode laser. The aim of the study was to explore the industrial applications of the HPLD and to understand the basic characteristics of the involved processes.

\subsection{Marking and engraving natural stones}

Experiments were conducted for marking and engraving marbles and granite using the Diomed HPLD. These materials are often seen in buildings and monumental cemeteries. Inscription on these materials is extremely difficult and time consuming based one the current mechanical chiselling carried out by stone masons. This research work aimed to study the feasibility and effects of using the diode laser for flexible engraving and marking on these materials. The compactness, reliability and ease of use of diode lasers would greatly benefit the process compared to using other types of lasers.

5.1.1. Engraving marble : Marble is a metamorphic rock composed of recrystallized calcite or dolomite with impurities of quartz chalcedony, hematie and pyrite, as well as some organic compounds [18]. The main 
component of marble ( $95 \%$ by mass) is $\mathrm{CaCO}_{3}$ lime stone, which breaks down at temperatures between $825^{\circ} \mathrm{C}$ and $950^{\circ} \mathrm{C}$ in accordance with the recognised chemical reaction [19]:

$$
\mathrm{CaCO}_{3}=\mathrm{CaO}+\mathrm{CO}_{2}-42.52 \mathrm{kcal} / \mathrm{mole} .
$$

Such temperatures can easily be achieved with power densities as low as $10^{3}-10^{5} \mathrm{~W} / \mathrm{cm}^{2}$. As one can see, the breakdown results in carbon dioxide gas $\left(\mathrm{CO}_{2}\right)$ and unslaked lime $(\mathrm{CaO})$ which adheres loosely to the unprocessed substrate beneath and can be easily removed with assisted gas.

Marbles of different colours (uniform black, uniform blue, uniform off-white and multi-coloured) were irradiated with the Diomed $60 \mathrm{~W}$ diode laser with powers ranging from $35 \mathrm{~W}$ to $50 \mathrm{~W}$, spot diameter of $2 \mathrm{~mm}$ and processing speed of $1-10 \mathrm{~mm} / \mathrm{s}$. At the same time a coaxial Argon gas jet of 6-201/min was applied to the meltpool to remove the loose $\mathrm{CaO}$ which was sucked away with a closed-up extraction nozzle. The experiments showed that for darker uniformly coloured marbles, engraving depths of $0.1 \mathrm{~mm}$ to $0.75 \mathrm{~mm}$ per pass with engraving width of 1 to $2 \mathrm{~mm}$ can be achieved with little heat affected zone. No cracks were seen on the untreated part and edges were clean as shown in Figure 1. A relationship between the engraved depth and processing speed under various laser power densities is given in Figure 2. Multiple passes were used to produce deeper engraved lines. The advantages of technique over the existing mechanical means and other pulse laser marking techniques are that wider and deeper lines can be engraved with high efficiency and precision, and the whole process can be computer controlled. Since there is no need to vaporise or even melt the material, the energy efficiency is relatively high.

\section{Un-engraved part Engraved groove}

(a)

Figure 1. a) An example of HPLD engraved grey marble tile (operating parameters: 50W, $2 \mathrm{~mm}$ beam diameter, $10 \mathrm{~mm} / \mathrm{s}$ traverse speed in two passes). b) Microscopic picture showing the edge quality of the engraved groove, x 50 .

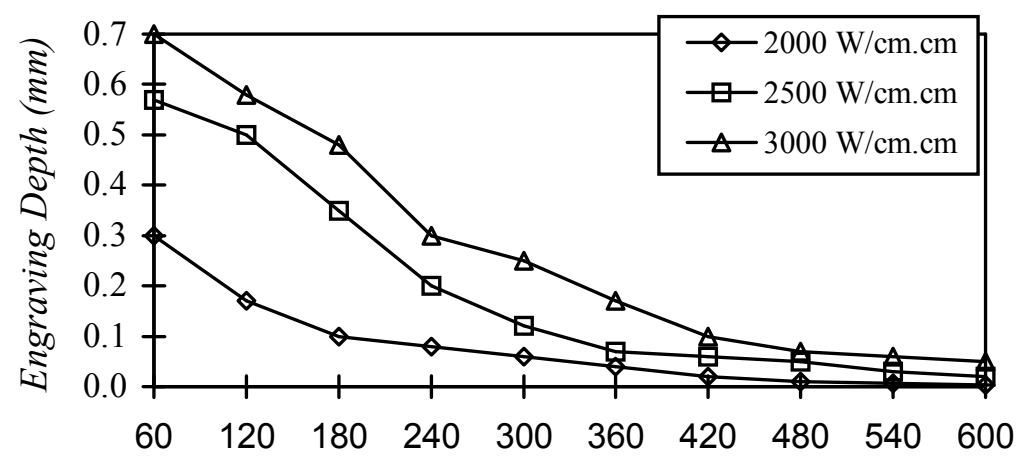

Traverse Speed ( $\mathrm{m} / \mathrm{min})$

Figure 2. Relationships between diode laser processing speed and marble engraving depth.

For multi-coloured marbles with and pale coloured marbles, it was more difficult to produce uniform engraving lines directly using HPLD. The light coloured marbles displayed almost $100 \%$ reflection to HPLD beam, whist the characteristic white vein that occurs in many marbles also reflect most of the DPLD beam. To overcome the 
problem, a black water based ink was applied to marble surface with thickness of less than $0.01 \mathrm{~mm}$ prior to laser processing. This had improved process efficiency significantly, with uniformly single pass engraved depth to around $0.5 \mathrm{~mm}$ on light beige, multi-coloured and white marbles with laser power of $50 \mathrm{~W}$.

Figure 2. Examples of diode laser engraved marble tiles. (a) surface (b), cross section

Marking granite: Granite is a crystalline igneous rock that consists mainly of quartz $\left(\mathrm{SiO}_{2}\right)$, alkali feldspar and plagioclase, typically $80-100 \%$ by volume, and other accessory minerals such as biotite, magnatite and zircon, around $20-0 \%$ by volume [20]. As such, the laser induced chemical reactions that occur are very different to those experienced by marble. Various types of granite tiles were irradiated using the Diomed $60 \mathrm{~W}$ diode laser operating in CW mode with powers of $30-60 \mathrm{~W}$ and spot size of $2 \mathrm{~mm}$. The traverse speed were varied from 1 to $10 \mathrm{~mm} / \mathrm{s}$. After laser processing a dark green porous vitrified glazed mark was seen on the laser processing tracks as shown in Figure 3. Since one of the major constituents of the granite is quartz, which is almost $100 \%$ silica, the resultant glazing effect is believed to be largely vitrified silica after the granite is melted by the laser beam. This has produced a permanent mark on the granite tiles. The glazed lines are found uniform although the glaze is slightly porous which could be removed by mechanical means afterwards if necessary. The multi-colour grant processing exhibited similar problems as for marble and the application of an absorbent ink was used successfully to enable uniform marking. An experimental relationship between the marking (glazing) depth and laser processing parameters is shown in Figure 4.

(a)

(b)

Figure 3. Examples of laser marked multicoloured granite. $50 \mathrm{~W}, 8 \mathrm{~mm} / \mathrm{s}$ a) distant view b) microscopic view $\mathrm{x}$ 50 


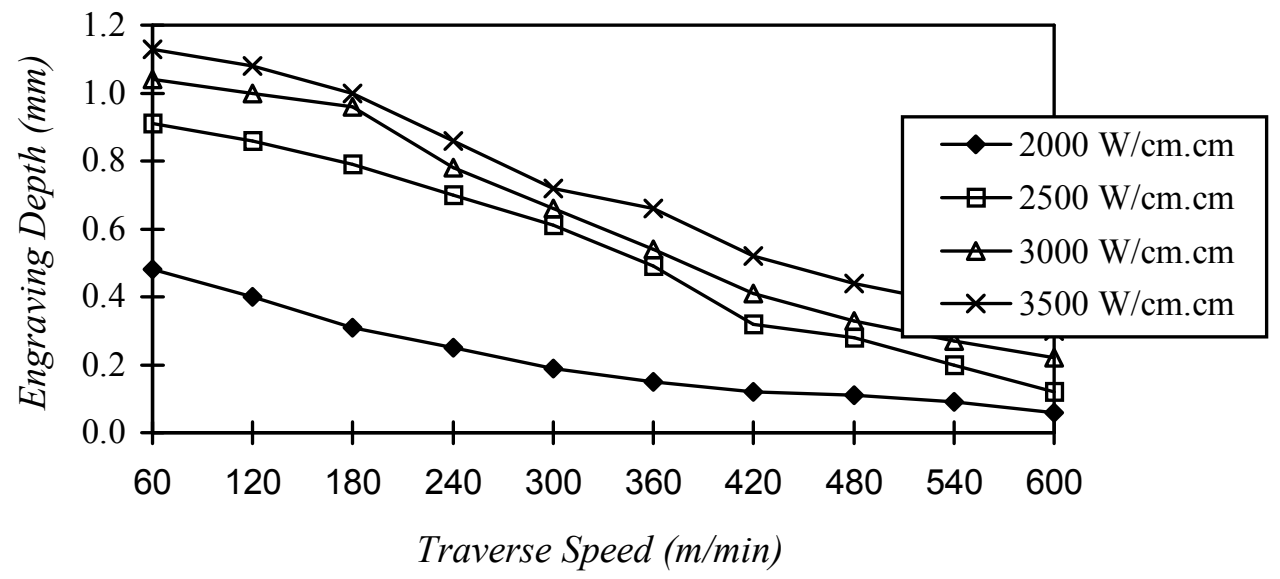

Figure 4. Experimental relationships between diode laser processing parameters and marking depth on granite.

\subsection{Marking ceramic tiles and chinaware}

Chinaware are seen in everyday life such as tea cups, ceramic plates and vases etc. Ceramic tiles are also used in domestic and industrial environment for floor and walls tiling. Currently the decorations on these ceramic items are largely carried out either by painting before glazing or by mechanical engraving or by chemical etching during the manufacturing stages of the tiles. The aim of the this study was to investigate the feasibility and characteristics of flexible marking on finished ceramic products by using a diode laser.

Tiles: Ceramic tiles of various types (vitrified and clay quarry tiles) were marked using the Diomed diode laser. These tiles consist of $53 \%$ (for vitrified tiles) to $72 \%$ (for clay quarry tiles) ball clay $\left(70 \% \mathrm{SiO}_{2}, 19 \% \mathrm{Al}_{2} \mathrm{O}_{3}\right.$, $1.6 \% \mathrm{TiO}_{2}, 2 \% \mathrm{~K}_{2} \mathrm{O}, 0.8 \% \mathrm{Fe}_{2} \mathrm{O}_{3}, 0.5 \% \mathrm{NaO}, 0.4 \% \mathrm{MgO}$, and $0.2 \% \mathrm{CaO}$ ), and other materials such as limestone (5-10\%), silica (10-24\%) and reprocessed tile (13\%). Laser markings on these tiles were produced by producing codification phases of the tile materials which result in glazed tracks of different colours from those of the tiles. This was achieved by laser melting of tiles at operating parameters of $20-30 \mathrm{~W}, 1-2 \mathrm{~mm}$ spot diameter and traversing speed of $2-10 \mathrm{~mm} / \mathrm{s}$. The experiments showed that while tiles reflected almost all of the laser beam leaving no marks at all unless an absorbent ink was applied prior to laser marking, while beige (such as the back of the white vitrified tiles) or darker coloured (such as brown clay quarry tiles) tiles can be marked easily using the Diomed diode laser. The colour of the glaze is dependent on the tile material used. Uniform lines of 0.5 to $2 \mathrm{~mm}$ with good edge quality were produced on both types of tiles with the line width on the clay quarry tiles half of that on the back of vitrified tiles for the same operating conditions (Figure 5 c.d). It is expected that by applying different oxide materials on the surface before laser processing, marked patterns of different colours can be developed after laser glazing. 
Figure 5. Laser marking on ceramic tiles. a) distant view of diode laser generated marks on the back of a vitrified ceramic tile. b) distant view of the diode laser generated marks on a clay quarry tile. c) microscopic view of marked line on the vitrified ceramic tile, x 25, d) microscopic view of marked line on the clay quarry tile, x 25 .

Engraving on chinaware: A domestic ceramic plate was marked using the HPDL of $40 \mathrm{~W}$ by the melt and blow process (gas flowrate of $201 / \mathrm{min}$ ). The engraved lines, where the glaze was removed exposing the porous substrate, were then coloured by spraying pigmented solution (ink) which soaked into the porous engraved part whist the paint on the untreated part was wiped out using a cloth. An example of the marked china plate with multi-colour pigmentation afterwards is shown in figure 6 .

Figure 6. A domestic ceramic plate decorated by the HPLD.

\subsection{Glazing enamels for sealing tile grouts}

Ceramic tiles are applied to walls and floors in hospitals, public lavatory, restaurants and biological/nuclear laboratories. The predominant problems with commercial available tiles grouts in between the tiles is that over time they become contaminated with dirt, germs and other harmful agents due to the porous nature of the material. If the tile grouts can be sealed with a layer of glazed facing so that it becomes impervious to contaminating agents, the appearance, hygiene and the life of the tile grouts can be improved. In nuclear processing plants, the use of totally sealed tiling could reduce the radioactive contamination to the building. Also the tiling with sealed grouts could also beused for contamination tie-down during nuclear decommissioning. The aim of this study was to investigate the feasibility of sealing the tile grouts using a high power diode laser. The study showed that the existing tile grouts are not suitable for sealing or glazing using laser beams. This is because large quantity of organic substances exist in the tile grouts as binding agents which upon heating will disintegrate and cause charring of the grouts. Therefore a new grout formula was developed to suit the laser glazing or sealing. It has been found through numerous experiments that a chammotte based compound can be used as the heat resistant base grout while a low softening point enamel was used in the top layer. After irradiation by the diode laser beam of $30 \mathrm{~W}$ power at traversing speed of $3 \mathrm{~mm} / \mathrm{s}$, a layer of glassy surface was formed on the top layer of the grouts and sealed (weld to ) with the tiles. The formed surface has no cracks or 
porosity. No pre-heating was required unlike most of previously reported laser glazing techniques. Details of this work are presented in a separate paper [21].

\subsection{Cutting and marking glass}

To date a fair amount of research has been conducted to investigate cutting glass with lasers such as the work of Kurobe et al [22], Schaeffer et al [23] and Chen et al [24]. The work reported here was to replicate these studies using a HPLD and to access any advantages or disadvantages of HPLD. $2 \mathrm{~mm}$ thick soda-lime-silica glass was cut with the Diomed $60 \mathrm{~W}$ diode laser operating at $50 \mathrm{~W}$ to $60 \mathrm{~W}$ and a beam spot diameter of $2 \mathrm{~mm}$ and traversing speed of $5-10 \mathrm{~mm} / \mathrm{s}$. When the glass was not coated with an absorbent ink, 10 passes were needed to complete the cut. When a black water based ink was applied (less than $0.01 \mathrm{~mm}$ thick) to the glass prior to laser cutting, only 4 passes were required operating at $50 \mathrm{~W}, 10 \mathrm{~mm} / \mathrm{s}$ and a beam spot size of $2 \mathrm{~mm}$.

It was observed during the experiments that the HPLD cutting process, for both coated and un-coated glass samples, was the result of the development and propagation of thermally induced stress cracks. The cracks can be best initiated at the outer edge of the samples, perpendicular to the surface, where the beam was first incident upon the glass. They then propagated across the glass, consistently following the laser path locus and increasing in length with each pass. The directionality of the cuts was quite reasonable, deviating only approximately $0.5 \mathrm{~mm}$ from the laser path locus for a cut length of $40 \mathrm{~mm}$ for un-coated glass samples. Such a deviation was also recorded by previous workers using YAG and $\mathrm{CO} 2$ lasers [22, 25]. The cut surface profiles of the HPLD cut samples as shown in Figure 6(a) were found very smooth and clean not displaying the typical rough, undulated appearance characteristic of the cur surface profiles produced by mechanical methods.

To mark on the glass, a black water based ink was applied prior to laser marking. Higher traversing speed $(20 \mathrm{~mm} / \mathrm{s})$ was used compared to marking. One or two passes were found sufficient to generate microcracks near the surface. There is no need to initiate cracks from the edge of the glass. Laser marking can be initiated from anywhere on the class. No deviation of the mark from the laser path was recorded, even when complex geometry such as circles were marked (shown in Figure 6b). Difficulty of cutting small curvatures were reported for $\mathrm{CO}_{2}$ and YAG lasers due to deviation from the laser tracking locus [22].

(a)

Figure 6. a) Cross section of a glass cut by the HPLD, $x^{* * *}$ b) Surface appearance of a glass marked by the HPLD, $\mathrm{x} * * *$.

\subsection{Marking/engraving wood}

The utilisation of lasers, in particular $\mathrm{CO}_{2}$ lasers, for marking on wood is an established area of research which has identified a number of unique advantages [26] and Swaczyna et al [27]. The results reported here were an attempt to examine the ease with which wood marking may be carried out suing a HPLD. A limited domestic wood board with a common pine pale wood on the surface was marked and engraved with the HPLD. Engraving parameters used for this wood were $40 \mathrm{~W}$ power at 1 to $2 \mathrm{~mm}$ beam spot and 2 to $30 \mathrm{~mm} / \mathrm{s}$ traversing speeds. Depths of 0.5 to $4 \mathrm{~mm}$ grooves with clear edge quality were produced at the above parameters as shown in Figure $7 \mathrm{~b}$. For marking the wood using the diode laser much high speed $(35-40 \mathrm{~mm} / \mathrm{s})$ can be used for the laser power of $40 \mathrm{~W}$ and beam spot of $2 \mathrm{~mm}$. It has been found from the experiment that the marking line width is dependent on the direction of marking with uniform lines produced along the grains of the wood and non-uniform lines across the grains shown in figure 7. c. 
(a)

(b)

(c)

Figure 7. HPLD engraved and marked wood. a) Engraved wood top view (operating parameters: $10 \mathrm{~mm} / \mathrm{s}, 40 \mathrm{~W}$ and $1.5 \mathrm{~mm}$ beam spot size), b) engraved wood cross section view x 50. c) Marked wood showing direction dependence.

\subsection{Paint/lacquer removal}

Current method of laser paint removal is based on pulsed or Q-switched YAG and $\mathrm{CO}_{2}$ lasers aimed at removing paint without damaging the substrate. This has been largely applied to aircraft and helicopters to facilitate necessary periodic metallurgical inspection. The research work reported in the following describes the feasibility and characteristics of removing paint and lacquer from both metallic and non-metallic substrates. In this experiment a mild steel aerosol substrate $(0.22 \mathrm{~mm}$ thickness) with multi-coloured paint of around $40 \mu \mathrm{m}$ and a ceramic tile painted with $0.5 \mathrm{~mm}$ thick of lacquer were irradiated by the diode laser at various powers, beam spot sizes, traverse speeds and argon gas flowrate of 3-15 $1 / \mathrm{min}$ through the processing nozzle. The experiments showed that for effective, uniform multi-colour paint removal from metallic substrates (shown in Figure 8. b), laser power density has to be above a threshold of $1.5 \mathrm{~kW} / \mathrm{cm}^{2}$ and traversing speed below $20 \mathrm{~mm} / \mathrm{s}$ at the threshold power density, i.e. a minimum of $0.75 \mathrm{~J} / \mathrm{mm}^{3}$ is required. If the energy delivery rate is below this level non-uniform paint removal may result in which laser beam was reflected by the red and white coloured paints (figure 8.a, the middle line). Although no surface damage was visible to the substrate where the paint had been removed, bending of the sample in the direction of laser had occurred around the irradiated path. This is partly due to the fact that the substrate material used was very thin thus heat dissipation rate is low. Removing paint/lacquer from ceramic tiles was found to require much less energy than that for metal substrate. For example operating a $20 \mathrm{~W}$, beam spot size of $3 \mathrm{~mm}$ and traversing speed of $25 \mathrm{~mm} / \mathrm{s}$, the $0.5 \mathrm{~mm}$ thick lacquer was removed $100 \%$ to substrate. 
Figure 8. An example of HPLD removal of multi-coloured paint from metal substrate. a) Distant view, b) closed up view.

\subsection{Welding metal wires}

A paper clip was welded (figure 9) by the HPLD at powers of $55 \mathrm{~W}$ and beam spot size of $1 \mathrm{~mm}$ and interaction time of 3 seconds. This shows the feasibility of applying the HPLD for a range of welding applications including wire mesh welding, jewellery repair etc.

Figure 9. A paper clip welded by the HPLD, x 50

\section{DISCUSSION}

4.1. Interaction of HPLD with metallic materials: From our experiments we found that although theoretically shorter wavelength of HPLD should have better beam absorption than YAG and CO2 lasers for metals, since the diode laser is currently limited to very low power, little effect can be generated on large metallic sheets due to high thermal dissipation rate. So far we have been only successful of welding and treating thin wires and thin sheets (such as hardening of saw blades and razor blades) of low overall mass volume using HPLD.

4.2. Interaction of HPLD with ceramics, organic and non-metallic materials: Beam absorption by these materials have been found to vary with surface colouring with red and while colour reflecting most of the laser beam. However when an absorbent ink is applied, almost all types of surfaces can be treated with significant thermal effects for the treated part and little heat affected zone next to the laser interaction zone. This type of materials is found to suit the current power levels of the high power diode laser very well.

4.3. Comparison with $\mathrm{CO} 2$ laser and YAG lasers: The unique features of diode laser is its portability and reliability. The weaknesses of diode laser in price and power are only temporary. Beam mode could be improved as for YAG lasers. It is expected that in the near future HPLD may find its market in portable devices, flexible desk top devices.

\section{CONCLUSIONS}

Basic characteristics and state of art of high power diode laser technology together with existing R\&D work in materials processing using HPLD have been reviewed. New applications of the HPLD for materials processing have been investigated by the authors are described. The investigations showed clearly the potential of using high power diode laser as a flexible desk-top system for:

- marking/engraving marble and granite - a potential market in monumental services

- marking ceramic tiles and glass - a potential market in domestic chinaware decoration

- sealing tile grouts - a potential market in hygienic treatment in restaurants and publish lavatories

- marking wood - furniture and

- cutting glass - building and computer storage

- welding wire and wire mesh - manufacturing industry and jewellery

- selective paint removal - portable graffiti removal, laser vacuum cleaner

- hardening - manufacturing industry for tool tips, saw blades, knife edges etc.

Many are unique to the diode laser; portability, low running costs, etc.. Through these studies, an understanding of the characteristics of interactions between diode laser beam with various materials was gained. Desk top systems, fibre optic delivery enables multi-axis processing system easily, 


\section{ACKNOWLEDGMENTS}

The authors would like to express their gratitude to EPSRC (process engineering group) for the support of diode laser and CNC equipment, EPSRC (CDP group) for a CASE studentship, BNFL (contract number) and and Diomed Ltd for supporting analystical equipment, part of rsearcher living expenses and running costs of the project., Nuffield foundation (award number) for their finacial support to the project.

\section{REFERENCES}

Chen, W., Roychoudhuri, C.S., Banas, C.M.. (1994), "Design Approaches for Laser Diode Materials Processing Systems Using Fibres and Mico-optics", Optical Engineering, Nov.1994, Vol 33 (11), pp3662-3669.

Forest, G.(1993), "Coupling High Power Laser Diodes to Applications", Lasers \& Optronics, March 1993, Vol 12(3), p10.

Gilbert, G., (1995), "Laser Soldering With High Power Laser Diodes", Proc. of the Institute of Physsics Quantum Electronics Group Meeting: Direct applications of High Power Laser Diodes, Nov. 1995, London, UK. Vol 1 (8).

Krause, V., Treusch, H.G.Beyer,E., Loosen, P., (1992), "High Power Laser Diodes as a Beam Source for Materials Processing", Proc. of the European Conference on Laser Treatment of Materials, May 1992, Gottinggen, Germany, p27-32.

Tonshoff, H.K., Berndt, A., Sturmer, M., Golla,D., and Schumacher, J., (1994), "Diode Lasers for Materials Processing", Journal de Physique, April 1994, vol 4 (3), p59-63.

Zediker, M.S., (1993), "Direct Diode Laser Competes with Nd:YAG and $\mathrm{CO}_{2}$ " Industrial Laser Review, Aug. 1993, p17.

Patent: BNFL:

4 patents:

\begin{tabular}{|l|l|l|l|l|l|}
\hline $\begin{array}{l}\text { Organisation } \\
\text { s }\end{array}$ & $\begin{array}{l}\text { McDonnell Doglas } \\
\text { Aerospace } \\
\text { (USA) }\end{array}$ & $\begin{array}{l}\text { Sony } \\
\text { (Japan) }\end{array}$ & $\begin{array}{l}\text { University of } \\
\text { Connecticut } \\
\text { (USA) }\end{array}$ & $\begin{array}{l}\text { Laser Zentrum } \\
\text { Hannover eV } \\
\text { (Germany) }\end{array}$ & $\begin{array}{l}\text { University } \\
\text { of Hull } \\
\text { (UK) }\end{array}$ \\
\hline $\begin{array}{l}\text { Activities in } \\
\text { materials } \\
\text { processing }\end{array}$ & $\begin{array}{l}\text { Cutting, Drilling, } \\
\text { soldering, marking } \\
\text { and welding }\end{array}$ & $\begin{array}{l}\text { surface } \\
\text { mount } \\
\text { soldering }\end{array}$ & $\begin{array}{l}\text { powder } \\
\text { sintering } \\
\text { hardening }\end{array}$ & $\begin{array}{l}\text { soft soldering } \\
\text { cutting }\end{array}$ & $\begin{array}{l}\text { micro- } \\
\text { soldering }\end{array}$ \\
\hline
\end{tabular}


Table 1. A summary of prinicpal features of various currently used high power lasers in materials processing industry with a comparison with high power diode lasers.

\begin{tabular}{|c|c|c|c|}
\hline $\begin{array}{l}\text { Type of } \\
\text { lasers }\end{array}$ & Adtanges & Disadvantages & Typical applications \\
\hline $\mathrm{CO}_{2}$ laser & $\begin{array}{ll}\text { - } & \text { highest everage power } \\
\text { (up to } 25 \mathrm{~kW}) \\
\text { - } & \text { high efficiency }(15 \%) \\
\text { - } & \text { good apsorption by } \\
\text { non-mettalic materials } \\
\text { - } & \text { good beam mode for } \\
\text { lasers up to } 5 \mathrm{~kW} \\
\text { - } \quad \text { relatively lower cost to } \\
\text { install and to run } \\
\text { - less safety requirement }\end{array}$ & $\begin{array}{ll}\text { - } & \text { beam can not be } \\
\text { delivered using optical } \\
\text { fibres } \\
\text { - } \text { poor absorption by } \\
\text { metals } \\
\text { - non-portable } \\
\text { - requires regular services }\end{array}$ & $\begin{array}{l}\text { sheet metal cutting, non- } \\
\text { mettalic materials marking, } \\
\text { welding, surface treatments } \\
\text { (hardening, alloying, cladding, } \\
\text { texturing, paint stripping and } \\
\text { surface glazing etc.), slotting, } \\
\text { rapid prototyping etc. }\end{array}$ \\
\hline $\begin{array}{l}\text { Nd-YAG } \\
\text { laser }\end{array}$ & $\begin{array}{l}\text { - high average power (up } \\
\text { to } 3 \mathrm{~kW} \text { ) } \\
\text { - high peak power of } \\
\text { pulsed beam } \\
\text { - beam transmittable } \\
\text { through optical fibres } \\
\text { - good beam absorption } \\
\text { for metals } \\
\end{array}$ & $\begin{array}{l}\text { - } \text { poor beam mode } \\
\text { - } \text { poor absorption by non- } \\
\text { mettalic materials } \\
\text { - } \text { surface colour sensitive } \\
\text { - high cost to install and to } \\
\text { - } \text { run } \\
\text { - } \text { non-portable } \\
\text { - high safety requirement }\end{array}$ & $\begin{array}{l}\text { Metal marking, drilling, multi- } \\
\text { axis robotic welding, } \\
\text { machining and paint stripping } \\
\text { etc. }\end{array}$ \\
\hline $\begin{array}{l}\text { Excimer } \\
\text { laser }\end{array}$ & $\begin{array}{l}\text { - highst peak power } \\
\text { - very short pulse (ns) } \\
\text { - good beam absorption } \\
\text { for both mettalic and } \\
\text { non-mettalic materials } \\
\text { - "cold" machining } \\
\text { possible }\end{array}$ & $\begin{array}{l}\text { - } \text { very high cost to install } \\
\text { and to run } \\
\text { - very high safety } \\
\text { requirement } \\
\text { - not tranmmittable } \\
\text { through optical fibres } \\
\text { - }\end{array}$ & $\begin{array}{l}\text { Micro-machining, surface } \\
\text { cleaning, ablation, PVD, CVD } \\
\text { etc. }\end{array}$ \\
\hline $\begin{array}{l}\text { Diode } \\
\text { laser }\end{array}$ & $\begin{array}{l}\text { - } \text { portable } \\
\text { - } \text { highest quantum } \\
\text { efficiency (up to } 40 \% \text { ) } \\
\text { - very long life (up to } \\
100000 \text { hrs) } \\
\text { - lowest running cost } \\
\text { - almost maintainence } \\
\text { free } \\
\text { - beam transmittable } \\
\text { through optical fibres } \\
\text { - good beam absorption } \\
\text { by metals } \\
\text { - potentially low cost to } \\
\text { install }\end{array}$ & 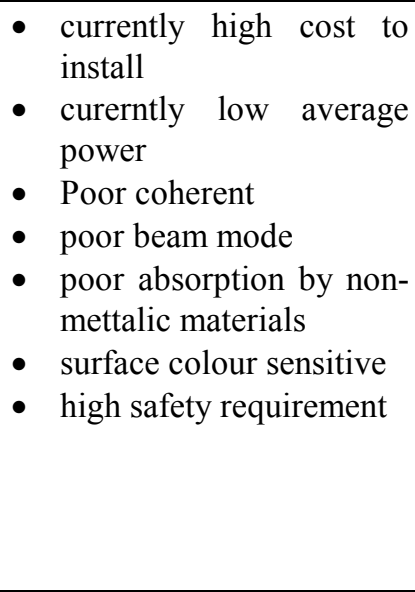 & $\begin{array}{l}\text { soldering, glazing, marking, } \\
\text { micro-soldering }\end{array}$ \\
\hline
\end{tabular}

